\title{
A Comparison of Face-To-Face and Videoconference Mentoring among Outpatient Physical and Occupational Therapists
}

\author{
Ann Marie Feretti \\ Regional Director of Occupational Therapy \\ MOTION PT Group \\ 160 East 56th Street, New York, NY 10021 \\ USA \\ Lori Kupczynski-Corresponding author \\ Professor, Doctor of Education Program \\ University of St. Augustine for Health Sciences \\ 1 University Blvd. \\ St. Augustine FL 32086 \\ USA \\ Shannon Groff \\ Professor, English and Education \\ Florida College at Jacksonville \\ 101 W. State St. \\ Jacksonville, FL 32202 \\ USA
}

\begin{abstract}
Physical and occupational therapists who have recently graduated and are beginning in their first professional positions often seek mentorship as they transition from school to clinical practice. The use of videoconference technology for mentoring meetings may provide more opportunities for novice clinicians to connect with experienced mentors to foster their professional growth and development. The purpose of these mixed methods, convergent design study was to compare the effectiveness of mentoring in face-to-face meetings to mentoring using videoconference meetings among newly graduated physical and occupational therapists. This study evaluated the effectiveness of mentoring meetings for physical and occupational therapy staff at a multi-site rehabilitation company. Results showed that there was no significant difference in the mentee's perception of effectiveness in the four mentoring areas of work setting relationships, clinical skill knowledgelattainment, career path/future planning and their role in the organization. The qualitative responses supported the idea that both mentees and mentors found value in using videoconference mentoring.
\end{abstract}

Keywords: mentoring, video mentoring, face-to-face mentoring, qualitative research

\section{Introduction}

Mentoring in the workplace is described as a relationship where a more senior employee guides, teaches, and coaches a more junior employee (Allen \&Dumani, 2017; Levinson \& Darrow, 1978; Kram \& Ragins, 2007). There is support for mentoring across disciplines, in business, in higher education, and in the healthcare professions (Doyle, Jacobs \& Ryan, 2016; Nowell, Norris, Mrklas \& White, 2017; Underhill, 2006). Mentoring is supported by the literature to improve job satisfaction, increase staff retention rates and benefit the communities served by healthcare professionals through decreased turnover and an increase in services that can be provided to patients (Stewart-Lord, Baillie, \& Woods, 2017; Trepanier, Early, Ulrich \& Cherry, 2012; Vergara, 2017). Buning and Buning (2018, Stewart-Lord, Baillie and Woods (2017), and Westervelt, et al. (2018) cite cost and lack of accessibility as barriers to clinicians being able to access mentorship programs. In an effort to find creative ways to overcome these barriers, a renewed focus on e-mentoring to support communication between mentors and mentees with schedule and geographic location limitations has evolved (Harris, Birk\& Sherman, 2016; Westervelt et al., 2018). 
Electronic mentoring, or e-mentoring is a new phenomenon that has developed with advances in electronic communication and includes mentoring relationships that occur at least partly with distance communication and not exclusively through in-person meetings (Bierema, 2017). E-mentoring encompasses a variety of communication forms including via telephone, emails, text messages, social media messaging or video conferencing.

There are benefits to exploring options for providing mentorship via the new technology available with synchronous video conferencing. It allows for real time discussions and questions that would not be possible when watching a prerecorded educational video alone (Greenberger \& Dispensa, 2015; van Duijn, Swanick \& Donald, 2014). Often, in the day-to-day scheduling of patient care, there will need to be adaptations and flexibility to facilitate mentoring. By having video conferencing as an option for mentor meetings with experienced clinicians, more inexperienced therapists can have increased access to a pool of clinical knowledge and experience.

This study addresses the problem of finding effective methods to provide mentoring to newly graduated occupational and physical therapists in an outpatient setting. Mentoring or mentorship is a topic that is current and relevant in outpatient occupational and physical therapy practice (Buning \& Buning, 2018; Fitzgerald, Moores, Coleman \& Fleming, 2015; Westervelt, et al., 2018).For novice occupational and physical therapists transitioning from academics and internships to practicing clinicians, mentoring with a more experienced therapist is a valuable way to build confidence and lifelong learning skills(McCombie \& Antanavage, 2017; Buning \& Buning, 2018). There has been recognition by the governing professional associations that occupational and physical therapists can benefit from the support of a more seasoned professional as they transition from their academic programs into clinical practice(American Physical Therapy Association [APTA], 2011; Conrad, 2011; Waite, 2014).

What has yet to be determined is the most effective and efficient way to deliver mentoring content with the least disruption to patient care. The existing research supports using a variety of methods of communication and delivering content but makes no judgment or claims that one is more effective than another (Buning \& Buning, 2018; Westervelt et al., 2018).

E-mentoring, using electronic communication methods to facilitate the mentor relationship and process, also called distance mentoring or virtual mentoring, has been described by different authors (Doyle et al., 2016; Haggard, Dougherty, Turban \& Wilbanks, 2011; Willbanks, 2014). E-mentoring has been described and well developed for the mentoring of junior faculty in academia and in mentoring online students (Doyle et al., 2016; Gottlieb et al., 2017; Nowell, Norris, Mrklas, \& White, 2017).Use of e-mentoring platforms, specifically video conferencing, could improve accessibility to mentorship. Part of the process in establishing effective mentoring programs includes determining the best methods of communication between mentors and mentees (Tiew, Koh, Creedy \& Tam, 2017). By examining both traditional face-to-face methods and newer technology such as video conferencing, clinicians will be able to confidently incorporate different methods of mentoring with the confidence that these methods are effective.

The purpose of this mixed methods, convergent design study was to evaluate the effectiveness of mentoring in face-toface meetings and video conference meetings among newly graduated physical and occupational therapists.

\section{Literature Review}

Mentorship is beneficial to both the mentor and mentee; however, it is an "asymmetrical relationship because it's primary purpose serves to facilitate transition of the novice into practice" (Gerhart, 2012, p. 52). In healthcare, mentoring provides experience, guidance and support to facilitate clinical and professional growth in new clinicians as they make the transition from their academic program (Mccombie \& Antanavage, 2017; Milner \& Bossers, 2005).

In healthcare professions, there is a well-documented need for support as novice clinicians transition from academia to clinical practice (McCombie \& Antanavage, 2017; Seah, Mackenzie \& Gamble, 2011; Tiew et al., 2017; Vergara, 2017). While researchers from the occupational and physical therapy fields have recommended mentoring students still in their academic programs, there is less published research on mentorship and the development of practicing clinicians transitioning from students to practice (Buning \& Buning, 2018; Milner \& Bossers, 2005; Tryssenear \& Perkins, 2001). A study that looked at an eleven-month mentoring program for occupational therapists working with the pediatric population found benefits to having a workplace program to facilitate professional development while encouraging peer communication and feedback (King et al., 2011). Results showed a significant positive effect on behaviors like selfconfidence, listening skills, family-centered activity and peer assessed clinical skills. There was no significant change in those qualities that were more disposition or general tendency traits including open mindedness, interpersonal sensitivity and interpersonal skills (King et al., 2011). 
Overall, it was concluded that an occupational therapy mentorship program was beneficial to the staff and the organization. The authors emphasized the importance of providing workplace opportunities for professional development and improving clinical skills (King et al., 2011). Similar conclusions were made for a mentorship program in acute care physical therapy (Carthas \& McDonnell, 2013). While instituting a new, structured mentorship program for physical therapists in the acute care setting, the authors stated that their mentorship program was a factor for newly graduated therapists in choosing the job.

Buning and Buning (2018) sought to identify the important components of a formal mentoring program for outpatient physical therapy from multiple stakeholders' perspectives. With respect to novice therapist needs, participants wanted ramped support in both workload, workplace functions like documentation and billing, guided experiences or cotreating opportunities, and guided opportunities to develop their skills (Buning \& Buning, 2018).

Buning and Buning (2018) raised concern about many of the barriers inherent to establishing a successful mentoring program. Discussing matching mentors with mentees, based on participant responses, the authors suggested that there should be flexibility in the matching of mentors and mentees. The researchers also listed barriers related to the limited availability in the schedule for mentoring opportunities and the decrease in revenue for private practice when there is a reduction in visits due to lost treatment time. Other barriers noted were understaffing, and tight schedules that both lead to inflexibility. Decreasing the workload for mentors and mentees for co-treatment and meeting means lost revenue which can be difficult to absorb for a small practice and which needs to be weighed against the potential benefits of mentoring.

\subsection{E-mentoring in rehabilitation}

Looking at e-mentoring specific to occupational and physical therapy, there is a growing but still limited body of research. What has been done, has primarily involved students in an educational environment. In a recent study that examined faculty mentors' perspective on e-mentoring post-professional occupational therapy doctoral students, researchers used a retrospective mixed-method study to understand the nature of e-mentoring relationships and what makes them most successful and satisfactory while understanding the impact of the mentoring relationship on students and faculty(Doyle et al., 2016). E-mentoring included a combination of web camera and telephone real time communication meetings as well as email communication between meetings. It was concluded that e-mentoring is successful when it is focused on the student or mentee, is flexible including in choice of technology to adapt to scheduling. However, consistently mentors preferred the face-to-face nature of web camera meetings, also known as videoconferences (Doyle et al., 2016). This corroborates previous research that frequent, structured meetings contribute to the success of and satisfaction with e-mentoring (deJanasz \& Godshalk, 2013; Eby et al., 2013). Faculty mentors in this study also corroborated that psychosocial support was an important component of mentoring (Doyle et al., 2016). This is consistent with Kram's (1985) seminal work in defining mentoring as a construct as well as research that supports the psychosocial support component of a successful mentoring relationship (Eby et al., 2013; Welch, 2017).

New research supports mentoring in physical and occupational therapy novice clinicians (Buning \& Buning, 2018; McCombie \& Antanavage, 2017; Westervelt et al., 2018; Yoon et al., 2017).There is not consistency with what should be included in a mentoring program or the best methods to provide mentoring opportunities. There is support for the use of technology to increase access to mentoring opportunities, but limited research about the effectiveness (Doyle et al., 2016; Westervelt et al., 2018). By increasing access to mentoring with distance e-mentoring methods, there are opportunities to facilitate development of clinical competence and independent practice in new occupational and physical therapy clinicians as they work through a transition from novice to expert.

Benner's (1984) Novice to Expert Theory describes development and acquisition of skills in nursing. This framework describes the five stages: novice, advanced beginner, competent, proficient, and expert as a guide of how healthcare practitioners develop clinical competence. An instrument to evaluate the effectiveness of a mentorship program was created for a nursing residency program (Tiew et al., 2017). The researchers that developed the NUH ME instrument also based their study on Benner's (1984) Novice to Expert model. By adapting this instrument for use in outpatient therapy, Benner's conceptual model can be applied to a mentorship program utilized in this setting.

\section{Methodology}

The aim of the study was to compare face-to-face mentorship communication with video conferencing methods of mentorship delivery. In this study, a mixed method, convergent design was used. Supporting the Novice to Expert conceptual model developed by Patricia Benner (1984), an adapted version of the NUH-ME survey developed by Tiew et al. (2017)was used to collect input from participants that evaluated their experiences with the one to one meetings in the mentoring program using both videoconference and in-person meetings. 
The qualitative data gathered from open ended questionnaires of both mentees and mentors explored perceptions on the use of e-mentoring with videoconference meetings as part of the mentorship program offered within the organization where participants work. The quantitative data was collected in multiple waves.

\subsection{Population and Sample}

Participants were recruited using a purposive sample. For this study, the potential sample was purposefully a group of physical and occupational therapists that work in the outpatient setting and have the opportunity to participate in both face-to-face and videoconference mentoring meetings. The company where the prospective subjects work offers a mentorship program to all clinical staff with less than two years of experience, as well as those clinicians who have more experience but may be transitioning to a new specialty area. The mentorship program has several components, including group lectures and hands-on clinical skills labs, a ramped up patient care schedule to gradually adjust to a full caseload, opportunities to co-treat patients with a mentor and the weekly one to one mentoring meetings that were specifically the focus of this research study. Permission was obtained to perform the study, exploring employee's perspectives about their one to one mentoring meeting experiences and the use of videoconferencing technology. All potential participants, occupational and physical therapists (approximately 75) employed at the outpatient rehabilitation provider group and participating in the established mentorship program, received an email with an invitation to participate in this study on mentorship and the use of technology if they fell into the mentee definition of less than two years of clinical experience or mentor definition if they have greater than five years of experience. A total of 44 participants registered to participate by completing the demographic survey. They were divided into groups of mentors and mentees based on their years of experience and their role at the time in the mentorship program. Mentors were primarily defined by five or more years of practice with prior supervisory experience. There were 3 participating mentors that had less than five years of experience. Mentees were defined as those clinicians with less than two years of clinical experience.

The aim of the study was to evaluate the effectiveness of the 1:1 mentorship meetings using Zoom video conferencing and the effectiveness of face-to-face meetings. This population was well suited for this investigation as each novice clinician works in an outpatient facility, sometimes with minimal access to mentors on site.

Informed consent explanations were provided and all participants who completed the online surveys and questionnaires consented to participation through their completion of the surveys and questionnaires. All participants were provided with an informed consent document prior to participating. Participation was completely voluntary. Once a participant was included, there was no identifying information on collected surveys. Employment or advancement was not affected by decision to participate or not.

Mentees had weekly one to one mentorship meetings, with opportunities to meet with mentors in their own clinics if available, as well as opportunities to access mentors in other specialties at other clinics via live video conferencing. Mentor meetings were logged weekly. This weekly mentoring meeting process was occurring before the study and continued after. After each weekly meeting, mentees completed a survey on that particular meeting, noting if it was inperson/face-to-face or used video conferencing. A total of 58 surveys were collected. To ensure the data collection met the assumption of independence, that each response was independent from others, the data was analyzed using all 58 responses and only the responses that were from the first time that respondent was completing the survey for their specific type of mentoring meeting.

\subsection{Instrumentation}

Tiew et al. (2017) developed the NUH-ME instrument to measure the perceptions of a structured mentorship program for newly graduated nurses. They established face validity with content experts, and content validity using the content validity index with those experts (Tiew et al., 2017). The researchers reported a content validity index of at least $90 \%$ on all items. There was also psychometric testing of the draft 10-item NUH-ME tool. Initially, researchers developing this tool administered the tool to a development sample group. It was with this initial administration that they performed test-retest reliability and results were examined using intra-class correlation coefficient (Tiew et al., 2017). The participants also completed the tool at the end of the mentoring program, when the internal reliability of the instrument was assessed using Cronbach's alpha and an exploratory factor analysis (Tiew et al., 2017).The original items were adapted to indicate physical and occupational therapy (instead of nursing) and named the rehabilitation organization as the employer. Open-ended questions were created to capture qualitative data during the study. These questions were distributed to 10 expert clinicians that had greater than 20 years of experience with clinical treatment and mentoring. Using the feedback provided by the expert clinicians, the final open-ended questions were finalized. The qualitative data provided the triangulation to confirm or collaborate findings from the quantitative data. 


\subsection{Method of Data Analysis}

In this study, the 19 items on the survey were divided into 4 main areas or categories that make up the research questions. By using an independent samples t-test for each category, the researcher assessed each area or research question and combined them into one result with a separate independent samples t-test that uses all 19 items on the instrument. When analyzing results, a p-value of $\leq 0.05$ was used for the independent samples t-tests, indicating a probability that the null hypotheses are true.

\section{Analysis of Data}

\subsection{Descriptive analysis of initial respondents}

Data indicated the typical study respondent was about 31 years old $(M=31.49, S D=9.19$, MIN/MAX=23-66), female $(n=31,70.5 \%)$, reported physical therapy as a profession $(n=36,81.8 \%)$, was either in practice for $0-6$ months $(n=16$, $36.4 \%)$, the mentees, or $5+$ years $(n=16,36.4 \%)$, the mentors, worked full-time $(n=44,100.0 \%)$, had not had prior experience with a formal mentoring program $(n=34,77.3 \%)$, and had used video conference technology before $(n=35$, $79.5 \%)$. The length of time in practice also indicates that $54.6 \%$ of the initial respondents were mentees $(0-12$ months experience) and $43.2 \%$ of initial respondents were mentors (3+ years of experience). The single respondent that had 1-2 years of experience was also participating as a mentee.

\subsection{Quantitative analysis}

\subsubsection{Descriptive analysis}

Data indicated that the scores for the dependent variable scales ranged between 7.16-7.75 for the Work Setting Relationships scale ( $M=7.75$. SD=1.53), Clinical Skill Knowledge Development scale (M=7.34, SD=1.43), Career Path \& Future Planning scale $(\mathrm{M}=7.16, \mathrm{SD}=1.55)$, Contributing to the organization/Role in Clinic scale $(\mathrm{M}=7.32, \mathrm{SD}=1.65)$, and Effective Mentoring scale $(\mathrm{M}=7.39, \mathrm{SD}=1.44$. Ratings regarding mentoring type were about two-thirds Face-toFace $(n=39,67.2 \%)$ and one-third Video Conferencing $(n=19,32.8 \%)$. The groups of participants were not equal for face-to-face mentoring and video conference mentoring. The study attempted to measure the mentoring program as it currently exists and is being used and did not attempt to control what was happening organically in the workplace.

\subsubsection{Inferential analysis}

Each quantitative main category was tested using an independent samples t-test. The results are presented in a table format to be able to visually compare each variable and corresponding test results as seen in Table 1 . For each of the main categories, Table 1 shows that $p>.05$, meaning that there was no statistically significant difference in the mean scores when comparing the face-to-face group to the videoconference group.

Table 1. Independent Samples T-Test Analysis of Outcome Scores by Face-to-Face In-Person vs. Video Conference Mentoring ( $\mathrm{n}=58$ )

\begin{tabular}{|c|c|c|c|c|}
\hline Variable & $\mathbf{n}$ & M (SD) & $t /(\mathbf{d f})$ & $\mathbf{p}$ \\
\hline \multicolumn{3}{|l|}{ Work Setting Relationships } & $.83(51.57)$ & .41 \\
\hline Face-to-face in-person 39 & & $7.85(1.71)$ & & \\
\hline Video Conference & 19 & $7.54(1.10)$ & & \\
\hline \multicolumn{3}{|c|}{ Clinical SkillKnowledge Development } & $1.00(55.34)$ & .32 \\
\hline Face-to-face in-person 39 & & $7.45(1.63)$ & & \\
\hline Video Conference & 19 & $7.12(.88)$ & & \\
\hline \multicolumn{3}{|c|}{ Career Path \& Future Planning } & $1.64(56)$ & .107 \\
\hline Face-to-face in-person 39 & & $7.38(1.71)$ & & \\
\hline Video Conference & 19 & $6.68(1.04)$ & & \\
\hline \multicolumn{3}{|c|}{ Contributing to the organization/Role in Clinic } & $.91(56)$ & .37 \\
\hline Face-to-face in-person 39 & & $7.46(1.77)$ & & \\
\hline Video Conference & 19 & $7.04(1.36)$ & & \\
\hline \multicolumn{3}{|c|}{ Effective Mentoring (Total Scale Score) } & $1.09(56)$ & .28 \\
\hline Face-to-face in-person 39 & & $7.53(1.61)$ & & \\
\hline Video Conference & 19 & $7.09(.98)$ & & \\
\hline
\end{tabular}

\subsection{Qualitative analysis}

Twenty-two participants completed the open-ended questionnaire. More mentors than mentees completed the questionnaire. Of the overall mentors and mentees involved in qualitative analysis, a little over half the sample was female $(n=12,54.5 \%)$. 
The majority of the sample reported a profession of physical therapy $(n=17,77.3 \%)$, having been in practice for more than 5 years $(n=11,50.0 \%)$, worked full-time $(n=22,100.0 \%)$, had not had prior experience with a formal mentoring program $(n=16,72.7 \%)$, and had used video conference technology before $(n=19,86.4 \%)$. About two thirds of the group participated as a mentor $(n=14,63.6 \%)$ and one-third as a mentee $(n=8,36.4 \%)$.

Overall themes that were evident in responses were that the experienced mentors were interested in the mentorship program because they enjoy and value sharing their knowledge and experience with new clinicians, that they feel they learn from their mentees and that quality mentoring is important in the development of new clinical staff. Mentees overwhelmingly (100\% of responses) described their primary interest in mentoring being learning new skills from mentors.

Anticipating possible barriers to mentoring or limitations to the research, the next question asked respondents to describe their comfort level using video conference technology platforms. Across the board, participants answered that they were comfortable or somewhat comfortable using this technology.

Most mentees were consistent in their responses that face-to-face mentoring is more personal than video conferencing and it was easier to practice hands-on manual skills with in person face-to-face mentoring. Interestingly, one subject pointed out that video conferencing was face-to-face and with live video conferencing, participants did have the benefit of being able to read body language and non-verbal cues. There was also a general theme that video conference meetings were easy to schedule and $50 \%$ of mentees mentioned that video conference meetings were also good to overcome geographical barriers between mentor and mentee.

New clinicians were fairly consistent in their responses to weaknesses of face-to-face mentoring and weaknesses of video conference mentoring meetings. Difficulty scheduling time and geographic distance from their mentors were consistently weaknesses of face-to-face mentoring while difficulty practicing hands-on manual techniques and the lack of personal connection were weaknesses of video conference meetings as well as difficulty scheduling and the technical difficulties that can occur with live video conferencing.

Mentor responses were quite consistent with that of mentees when looking at perceptions of benefits with face-to-face mentoring and with live video conference mentoring meetings. Mentors also felt that face-to-face mentoring was more personal and better for demonstrating hands-on skills. Mentors overwhelmingly felt that video conference mentoring meetings were good for distance (71.4\% of answers included this), and many also mentioned ease of scheduling as a benefit for video conference meetings.

Similar to the mentee group, the mentors consistently saw it as a weakness of video conference mentoring that they could not as easily practice hands-on techniques. 50\% of mentors felt there was less personal connection, and $21 \%$ described the technical difficulties that can occur with video conference mentoring meetings as a weakness. Consistent with the mentee group, there were not many weaknesses described for face-to-face mentoring. The ones that were common to both groups were difficulties in scheduling and the geographic distance from mentees.

\subsection{Mixed methods data analysis and interpretation.}

When looking at the qualitative responses and some of the nuances expressed in the open-ended question responses, it shows that while mentees found both types of mentoring meetings effective, they did prefer face-to-face mentoring, especially when working on manual skills and wanting more hands-on demonstrations.

Specifically, in the area of work setting relationships, while the quantitative analysis showed no statistically significant difference, between face-to-face and video conference mentoring, many respondents (57\% of mentors and $63 \%$ of mentees) felt that face-to-face mentoring meetings were more personal.

For the area of clinical skill or knowledge development, there was also no statistically significant difference in the quantitative analysis for different mentoring types. In the qualitative data, both mentors and mentees reported that a benefit of face-to-face mentoring for developing their hands-on manual skills. There were several comments that described a benefit of having access to a wider variety of mentors and therefore to information and knowledge they may not be able to access in traditional face-to-face meetings in their regular work location.

For the area of career path and future planning, there was no statistically significant difference with face-to-face or video conference mentoring. There were no responses identified that supported one or the other types of mentoring meetings. There were several responses that described being involved in a structured mentoring program generally as helpful to develop leadership skills, and teaching experience. 
Finally, in the area of contribution to the clinic and organization, there was no statistically significant difference with face-to-face or video conference mentoring. The qualitative question that asked about participants' interest in mentoring provided many responses that were positive in nature about mentoring and the overall perception that a structured mentoring program in the organization was beneficial.

When questions were specific to differentiating between face-to-face and video conference mentoring, there were several responses that supported the use of video conference meetings for group sessions across multiple clinic locations. There was an appreciation for the ability to access a larger audience and a variety of mentors across a large organization through the use of video conference technology.

Effective mentoring overall, across each area also showed no statistically significant difference with face-to-face or video conference mentoring. When examining the qualitative responses, the themes that emerged from subjects' interest in participating in a mentorship program, there were common concepts across all results. The mentors and mentees wanted to share knowledge, learn skills, and seek guidance. Throughout the qualitative responses for all questions, there were responses that supported both face-to-face and video conference mentoring meetings. While there was more overall support and benefits described for face-to-face mentoring meetings, the limitations and barriers were consistent between mentees and mentors. Most participants reported that weaknesses of face-to-face mentoring were scheduling and geographic distance, both issues that mentees and mentors saw as a benefit for video conference mentoring. With the quantitative results showing no significant difference in the effectiveness for the type of mentoring meeting, the qualitative findings support resolving some of the barriers and weaknesses like scheduling and geographic distance by using video conference meetings. It is interesting that mentees and mentors prefer face-to-face meetings for clinical skill development while their responses on the quantitative survey show that there is minimal difference for developing these skills when using video conference mentoring.

\section{Conclusions}

Mentoring or mentorship is a topic that is current and relevant in outpatient occupational and physical therapy practice (Buning \& Buning, 2018; Fitzgerald, et al., 2015; Westervelt, et al., 2018). Participants in the current study echoed the importance of mentoring through their participation in the mentoring program and in the study, and specifically stated the value of mentoring in the workplace in their responses to open-ended questions. Subjects who were novice occupational and physical therapists transitioning from academics and internships to practicing clinicians, participated in an employer provided structured mentorship program with more experienced mentor therapists. Consistent with previous research, mentoring was described as a valuable way to build confidence and lifelong learning skills(McCombie \& Antanavage, 2017; Buning \& Buning, 2018).It has consistently been recognized by governing professional associations for occupational and physical therap ythat new graduate clinicians can benefit from the support of a more seasoned professional as they transition from their academic programs into clinical practice (APTA, 2011; Waite, 2014). The current study supports this idea in that the quantitative survey evaluated the effectiveness of mentoring with mean scores for mentoring effectiveness ranging from 7.16-7.75 on a scale of 1-10. Qualitative results corroborated the findings and were consistent with the idea that mentoring for new graduate occupational and physical therapy practitioners is beneficial. A primary theme in the responses was that mentoring is important and subjects provided numerous reasons why they wanted to participate in a mentorship program.

Consistent with the technological advancements of the $21^{\text {st }}$ century, mentoring is changing and adapting to leverage the benefits of some of the technological advances. E-mentoring, using electronic or computer facilitated communication methods to facilitate the mentor relationship and process also called distance mentoring or virtual mentoring, described by different authors, is becoming more prevalent across disciplines and practice environments (Doyle et al., 2016; Haggard et al., 2011; Willbanks, 2014). In response to different studies that called for more research on specific types of mentoring, and in response to raised concerns of barriers to mentoring programs, the current study was designed to address specific needs in the outpatient rehabilitation practice environment (Buning \& Buning, 2018; Haggard et al., 2011). Results showed that video conference mentoring meetings can be as effective as face-to-face mentoring meetings across multiple areas of mentoring. Results also showed that video conference mentoring can be implemented when there is difficulty scheduling or geographical barriers between mentee and mentor. The ability to overcome distance and scheduling issues is a known benefit for e-mentoring that was reinforced in this study (Westervelt et al., 2018). While qualitative responses were consistent with citing distance and scheduling difficulties as barriers to faceto-face mentoring, it was also consistently a benefit of using video conference mentoring.

There are multiple sources that report on the increase in job satisfaction and decreased turnover rate of newly graduated clinical staff who participate in mentoring programs (Trepanier et al., 2012; Vergara, 2017; Westervelt et al., 2018). Instituting a mentoring program can bring positive effects for the mentees, mentors, and for the organization (Buning \& Buning, 2018; Tiew et al., 2017). 
Specifically, in outpatient rehabilitation, challenges exist such as the mentor and mentee not being in the same geographic location, or even when there is an on-site mentor, schedules may not match up or there may be a clinical specialty which makes it so that the mentee would benefit from working with a different mentor for specialty practice. Use of e-mentoring platforms, specifically video conferencing, was shown in this study to provide increased accessibility as described by participants' responses to the qualitative questions. With the supporting evidence supplied by the results presented here, comparing the use of both traditional face-to-face methods and newer technology such as video conferencing; clinicians will be able to confidently incorporate different methods of mentoring with the confidence that these methods are effective.

\section{References}

Allen, T.D. \& Dumani, S. (2017). Mentoring. In S.G. Rogelberg (Ed.) The sage encyclopedia of industrial and organizational psychology $\left(2^{\text {nd }}\right.$ ed.) (pp.936-939). Thousand Oaks, CA: Sage Publications.

American Physical Therapy Association. (2011). Tap the APTA community for peer support and mentors. Retrieved January, 10, 2019, from http://www.apta.org/CareerManagement/Mentoring/PeerSupport/.

Benner, P. (1984). From Novice to expert. San Francisco, CA: Addison-Wesley Publishing.

Bierema, L. (2017). Ementoring: Computer mediated career development for the future. In D. A. Clutterbuck, F. K. Kochan \& L. Lunsford The SAGE Handbook of mentoring (pp. 482-497). 55 City Road, London: SAGE Publications Ltd. https://doi.org/10.4135/9781526402011.n30

Buning, M., \& Buning, S. (2018). Beyond supervised learning: A multi-perspective approach to outpatient physical therapy mentoring. Physiotherapy Theory and Practice, 35(3),243-258. https://doi.org/10.1080/09593985.2018.1443183

Carthas, S., \& McDonnell, B. (2013). The development of a physical therapy mentorship program in acute care. Journal of Acute Care Physical Therapy, 4(2), 84-89. https://doi.org/10.1097/01.JAT.0000436268.12583.4f.

Conrad, S. (2011). Finding your way. Perspectives magazine, (May 2011) Retrieved from http://www.apta.org/NewProfessionals/CareerManagement/FindingYourWay/

deJanasz, S.C., \& Godshalk, V.M. (2013). The role of e-mentoring in proteges' learning and satisfaction. Group \& Organization Management, 38(6), 743-774. https://doi.org/ 10.1177/1059601113511296.

Doyle, N., Jacobs, K., \& Ryan, C. (2016). Faculty mentors' perspectives on e-mentoring post-professional occupational therapy doctoral students. Occupational Therapy International, 23, 305-317. https://doi.org/10.1002/oti.1431

Eby, L.T., Allen, T.D., Hoffman, B.J., Baranik, L.E., Sauer, J.B., Baldwin, S., Morrison, M.A., Kinkade, K.M., Maher, C.P., Curtis, S., \& Evans, S.C. (2013). An interdisciplinary meta-analysis of the potential antecedents, correlates, and consequences of protégé perceptions of mentoring. Psychological Bulletin, 139(2), 441-476. https://doi.org/10.1037/a0029279.

Fitzgerald, C., Moores, A., Coleman, A., \& Fleming, J. (2015). Supporting new graduate professional development: A clinical learning framework. Australian Occupational Therapy Journal(1), 13. https://doi.org/10.1111/14401630.12165

Gerhart, L. A. (2012). Mentorship: A new strategy to invest in the capital of novice nurse practitioners. Nurse Leader, 10(3), 51-53. https://doi.org/10.1016/j.mnl.2011.09.011

Gottlieb, M., Fant, A., King, A., Messman, A., Robinson, D., Carmelli, G., \& Sherbino, J. (2017). One Click Away: Digital Mentorship in the Modern Era. Cureus, 9(11). https://doi.org/10.7759/cureus.1838

Greenberger, H. B., \& Dispensa, M. (2015). Usage and perceived value of video podcasts by professional physical therapist students in learning orthopedic special tests. Journal of Physical Therapy Education (American Physical Therapy Association, Education Section), 29(3), 46-57.

Haggard, D.L., Dougherty, T.W., Turban, D.B., \& Wilbanks, J.E. (2011). Who is a mentor? A review of evolving definitions and implications for research. Journal of Management, 37(1), 280-304. https://doi.org/10.1177/0149206310386227.

Harris, R., Birk, SB., \& Sherman, J. (2016). E-Mentoring for doctor of nursing practice students: A pilot program. Journal of Nursing Education, 55(8), 458-462.

King, G., Tam, C., Fay, L., Pilkington, M., Servais, M., \& Petrosian, H. (2011). Evaluation of an occupational therapy mentorship program: Effects on therapists' skills and family-centered behavior. Physical \& Occupational Therapy in Pediatrics, 31(3), 245-262. https://doi.org/10.3109/01942638.2010.523451

Kram, K. E. (1985). Mentoring at work: Developmental relationships in organizational life. Glenview, IL: Scott, Foresman.

Levinson, D. J., \& Darrow, C. N. (1978). The seasons of a man's life. New York: Ballantine Books. 
McCombie R.P. \& Antanavage, M. E. (2017). AntanavageMETransitioning from occupational therapy student to practicing occupational therapist: First year of employment. Occupational Therapy Health Care,31(2), 126142. http://doi.org/10.1080/07380577.2017.1307480

Milner, T., \& Bossers, A. (2005). Evaluation of an occupational therapy mentorship program. Canadian Journal of Occupational Therapy, 72(4), 205-211.

Nowell, L., Norris, J. M., Mrklas, K., \& White, D. E. (2017). Mixed methods systematic review exploring mentorship outcomes in nursing academia. Journal of Advanced Nursing, 73(3), 527-544. https://doi.org/10.1111/jan.13152

Seah, C. H., Mackenzie, L., \& Gamble, J. (2011). Transition of graduates of the Master of Occupational Therapy to practice. Australian Occupational Therapy Journal(2), 103.

Stewart-Lord, A., Baillie, L., \& Woods, S. (2017). Health care staff perceptions of a coaching and mentoring programme: A qualitative case study evaluation. International Journal of Evidence Based Coaching and Mentoring, 15(2), 70-85.

Tiew, L. H., Koh, C. S. L., Creedy, D. K., \& Tam, W. S. W. (2017). Graduate nurses' evaluation of mentorship: Development of a new tool. Nurse Education Today, 54, 77-82. https://doi.org/10.1016/j.nedt.2017.04.016

Trepanier, S., Early, S., Ulrich, B., \& Cherry, B. (2012). New graduate nurse residency program: A cost-benefit analysis based on turnover and contract labor usage. Nursing Economics, 30(4), 207-214.

Tryssenaar, J., \& Perkins, J. (2001). From student to therapist: Exploring the first year of practice. American Journal of Occupational Therapy, 55(1), 19-27.

Underhill, C. M. (2006). The effectiveness of mentoring programs in corporate settings: A meta-analytical review of the literature. Journal of Vocational Behavior, 68, 292-307. https://doi.org/10.1016/j.jvb.2005.05.003

van Duijn, A. J., Swanick, K., \& Donald, E. K. (2014). Student learning of cervical psychomotor skills via online video instruction versus traditional face-to-face instruction. Journal of Physical Therapy Education, 28(1), 94-102.

Vergara, J. Y. (2017). Implementation of a mentorship program to increase staff satisfaction and retention in critical care. Nurse Leader, 15, 207-212. https://doi.org/10.1016/j.mnl.2017.02.003

Waite, A. (2014). Guiding forces: Finding and benefiting from occupational therapy mentors. OT Practice, 19(17), 710.

Welch, S. (2017). Virtual mentoring program within an online doctoral nursing education program: A phenomenological study. International Journal of Nursing Education Scholarship, 14(1), 128. https://doi.org/10.1515/ijnes-2016-0049

Westervelt, K. C., Chenette, J., Merkel, L., Sibold, J., Crane, L., \& Hing, W. (2018). Postprofessional physical therapist education: A report from two regions of the world. Journal Of Physical Therapy Education, 32(3), 264-272. https://doi.org/10.1097/JTE.0000000000000036

Wilbanks, J.E. (2014). E-mentoring: Examining the feasibility of electronic, online, or distance mentoring. Journal of Higher Education Theory and Practice. 14(5), 24-28. 